\title{
MICROSTRUCTURAL AND PHYSICOCHEMICAL PROPERTIES OF SOME ALUMINUM COOKING TOOLS OBTAINED BY ARTISANAL RECYCLING
}

\author{
Pali KPELOU ${ }^{1 *}$, Essowè MOUZOU ${ }^{2}$, Essossinam AMINTI $^{1}$, Damgou MANI KONGNINE $^{1}$ \\ ${ }^{1}$ Department of Physics, Laboratoire sur l'Energie Solaire-Université de Lomé, Lomé, Togo \\ ${ }^{2}$ Department of Physics, Laboratoire de Physique des Matériaux et des Composants à Semi-conducteurs, \\ Université de Lomé, Lomé, Togo
}

\begin{abstract}
Recycling metals waste is one of the ways to recover this waste, but also to preserve mining resources and fight against pollution. Aluminum is one of the most recycled metals due to its relatively low melting temperature, high conductivity, ductility, malleability and its high resistance to corrosion. In Togo, as in many West African countries, aluminum wastes are collected, melted and molded in artisanal way to make new objects for domestic use. The aim of this work is to investigate the process of artisanal aluminum recycling and use several modern techniques of characterization in order to improve thereafter products and manufacturing process. Two types of samples were subjected to a series of physicochemical analysis. One from an old aluminum pot (sample (a)) and the other cut from newly pot obtained after artisanal manufacturing (sample $(b)$ ). The measurement of the temperature inside the crucible during scarp aluminum melting operation reveals three temperatures ranges with a melting point around $750{ }^{\circ} \mathrm{C}$. Atomic absorption spectrometry $(A A S)$ indicates that the two samples contain mostly aluminum, zinc, copper, magnesium and some traces of lead. Optical microscopy observations show that the alpha aluminum matrix was the most abundant phase with 80 to $90 \%$ of the observed area and some inclusions randomly dispersed. $X$-ray diffraction $(X R D)$ confirms the presence of lines characteristic of alpha aluminum and bohemite $(\gamma-\mathrm{AlOOH})$.
\end{abstract}

Keywords: recycling, artisanal, aluminum waste, cooking tools, physico-chemical, XRD

\section{Introduction}

For its interesting characteristics, aluminum is one of the most used minerals for the materials manufacturing. The lightness, the malleability, the thermal resistance and low corrosion susceptibility, make aluminum become an important material in many economic fields and productive sectors [1]. There's many aluminum components in the automotive, construction or home appliance industry. After steel, aluminum is one of the most used metals as household objects and utensils, such as soda cans, pots, pans, spoons, ladles, and aluminum foils with which food is wrapped.

Once produced, aluminum is infinitely recyclable, without any loss of its properties. However, to produce aluminum, the main used route is to extract this metal from bauxite (raw material for manufacturing); a considerable amount of energy is needed in this stage. The energy required to melt and recycle metals is much less than the energy needed to produce them from their mineral ore. Most others materials can be only reused whereas aluminum completely 
recovered to generate a new raw material. Like steel, aluminum wastes are very abundant. Aluminum and its alloys are more malleable and have lower melting point than that of steels. Recycling aluminum wastes materials presents therefore economic and environmental interests.

In addition, aluminum is more resistant to corrosion than iron alloys, and is a good heat conductor, which makes it a great choice for cookware with a thermal conductivity sixteen times greater than that of stainless steel [1]. As a result, these wastes are collected and transformed in an artisanal way into everyday objects in most developing countries. As described by Okunola et al [1], the artisanal recycling method does not require advanced training or complex equipment. The craftsmen founders recover the aluminum scrap and without any prior treatment proceed to the melting of these objects in a crucible. After melting, one or two pieces of dry cell battery are added to enable the impure materials to float and be removed from the pot [2]. The liquid metal is then poured into a clay mold to form the cast which will be removed from the mold after cooling [3], [4].

Beyond the ease offered by aluminum artisanal foundering, there are serious environmental impacts and human health concerns generated by the whole process of obtaining household aluminum objects.

The drawbacks of traditional method are related to the process and quality of products manufactured. Some objects such as cooking pots molded by artisanal way, undergoes perforations and become unusable after a few times of use. Furthermore, aluminum cookware's are produced from scrap metals including engine, vehicle radiators, lead batteries, computers parts and others materials without any control of their chemical composition. During their use as kitchen utensils, they leach harmful substances including heavy metals such as: nickel, arsenic, copper, cadmium, lead, and aluminum into food [5] which poses a public health effect depending on the quantity released.

Very few scientific studies [6] have been carried out to understand and improve the artisanal manufacturing process as well as the quality of the aluminum utensils and objects obtained by traditional means.

Therefore, the aim of this study was to understand the traditional recycling method by using modern techniques, to determined chemical composition and analyze microstructure of the cookware's parts produced. Understanding the process, the chemical and microstructural composition of an object will help determining the appropriate treatments and techniques for mitigating deterioration, damage, or preventing potential public health effects.

\section{Materials and Methods}

\section{Materials}

Two types of samples were involved in the present study for investigations: one taken from an old aluminum pot and the other cut from newly pot smelted by the founder (Fig. 1).
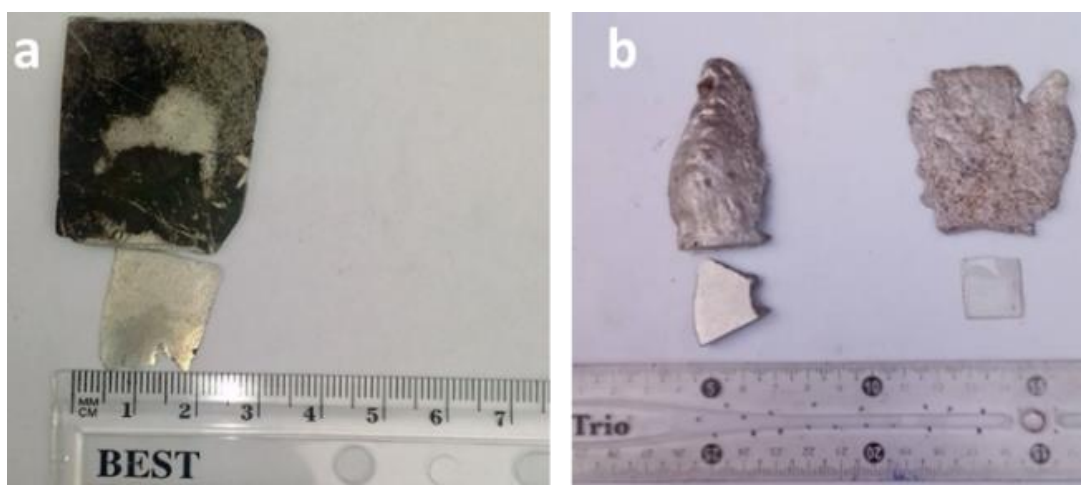

Fig. 1. Pieces of (a) aluminum old pot, (b) aluminum newly smelted 


\section{Temperature measurement}

The crucible temperature was measured in an artisanal foundry workshop located on the northern outskirts of the Lomé city (Togo). The specifics temperatures were recorded on two preparations made by the founder. Immediately after the introduction of the aluminum scarp into the crucible, the temperature values were reported every two minutes to determine the thermal profile. After complete melting of the aluminum scarp and just before casting into the mold, the casting temperature of the molten metal was recorded. The maximum temperature of the melting furnace was also recorded. The device used for the measurement is $\mathrm{k}$ type thermocouple equipped with a display whose measurement range is $(0-1300){ }^{\circ} \mathrm{C}$.

\section{Samples characterization}

Two types of samples were submitted to microstructural, chemical and structural analysis: samples from recycled old pot (sample a) and other one from newly melted pot (sample b). Their microstructures were studied using an optical microscope (OM). The samples were cut and mounted in acrylic resin, carefully ground with SiC 180-1200 papers. After the mechanical polishing step, samples were gently cleaned and then attacked using Fick's reagent (5\% hydrofluoric acid and $95 \%$ water) before microscopic observations. Samples were attacked by putting down a drop of the solution on the surface during 15 seconds followed by distilled water rinsing and air-drying before observations under optical microscope.

Atomic absorption spectroscopy (Model iCE 3000 SERIES THERMOFISCHER.), was performed to assess chemical composition. A 10 vol. \% nitric solution in deionized water was used to clean glassware used during the digestion procedure, to avoid any kind of contamination.

Diffraction pattern from recycled old pot were carried out using D2 PHASER Bruker $\mathrm{X}$ - Ray Diffractometer (XRD). The machine was equipped with a curved graphite crystal monochromatic and was operated with $\mathrm{Cu}$ anode $\left(\lambda_{\mathrm{Cu} \mathrm{Ka}}=1.54184 \mathrm{~nm}\right)$, an acceleration voltage of $40 \mathrm{kV}$ and a current of $30 \mathrm{~mA}$. The acquisitions were carried out at a scanning rate of $0.2 \%$. The scanning range was $5^{\circ}$ to $80^{\circ}$ for $2 \theta$ angle. Origin software was used to generate spectrum.

\section{Results and Discussions}

\section{Temperature evolution}

The thermal profile inside the crucible during aluminum scrap melting operation is shown in Fig. 2.

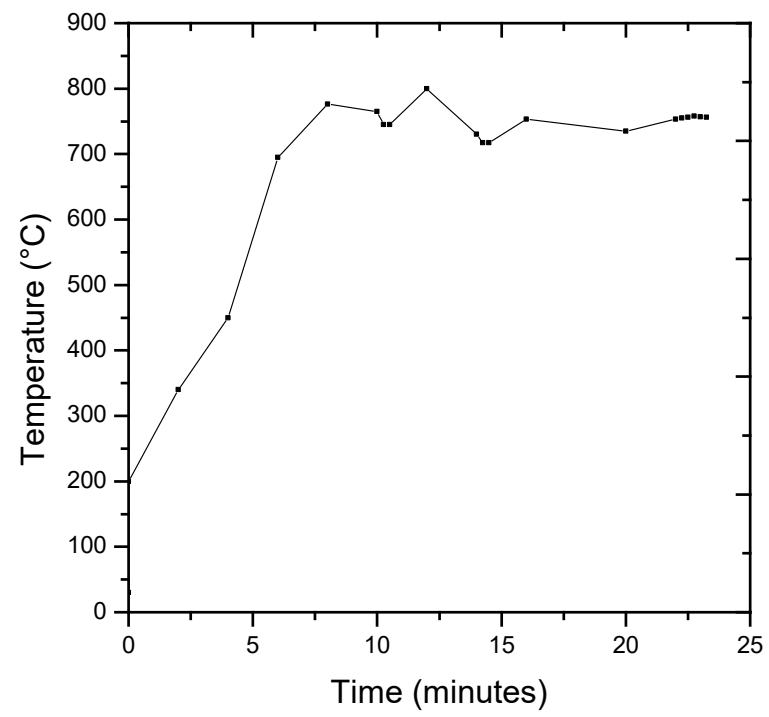

Fig. 2. Thermal profile inside the crucible during aluminum scrap smelting 
The thermal profile analysis reveals the presence of three temperatures ranges. The first zone presents a linear increase of temperature as a function of the time. In the second zone the temperature changes in a jagged way, it reaches a maximum value, decreases before stabilizing in the third zone where the temperature becomes constant over the time.

In the linear zone, the temperature increases rapidly $\left(1.4^{\circ} \mathrm{C} / \mathrm{s}\right)$ as a function of the time. This zone corresponds to heat transfer between aluminum scrap and crucible without any change in physical state. However, in the second zone, some aluminum scrap start smelting but due to the fact that all scraps were not homogenous and were not introduce in the crucible at the same time, that could justify the temperature fluctuation observed. In the third zone all the scrap reached their melting point, there is a phase change without temperature increase. The temperature remains almost constant for a given period; this corresponds to the phenomenon of phase change. The aluminum waste change from a solid state to a completely liquid phase. Following the thermal profile curve shown in Fig. 2, the melting temperature of aluminum scarp was estimated to about $750{ }^{\circ} \mathrm{C}$.

It's important to underline that during the smelting process, the hearth maximum temperature and the temperature before casting were reported and the obtained results were resumed in Table 1.

Table 1. Parameters for the production of magnetic composites

\begin{tabular}{cccc}
\hline $\begin{array}{l}\text { Hearth } \\
\text { temperature }\left({ }^{\circ} \mathrm{C}\right)\end{array}$ & $\begin{array}{c}\text { Temperature rise rate inside } \\
\text { the first zone }\left({ }^{\circ} \mathrm{C} / \mathrm{s}\right)\end{array}$ & Melting temperature $\left({ }^{\circ} \mathrm{C}\right)$ & $\begin{array}{c}\text { Casting temperature } \\
\left({ }^{\circ} \mathrm{C}\right)\end{array}$ \\
\hline 1100 & 1.4 & 750 & 830 \\
\hline
\end{tabular}

The high maximum hearth temperature of $1100{ }^{\circ} \mathrm{C}$ reported in the present study could have induced the high temperature rise rate recorded during the first phase of the smelting process.

\section{Chemical composition}

The chemical compositions of the tow samples analyzed using the atomic absorption spectroscopy (AAS) in the present work are reported in Table 2.

Table 2. Average chemical composition $(\% \mathrm{~m})$ of old and new recycled aluminum samples compared to Standard NF EN 601 (July 2004)

\begin{tabular}{|c|c|c|c|c|c|c|c|c|c|c|c|}
\hline Samples & Ca & $\mathbf{K}$ & Mg & $\mathbf{N a}$ & $\mathrm{Fe}$ & Cd & $\mathbf{P b}$ & $\mathrm{Cr}$ & $\mathrm{Cu}$ & $\mathbf{Z n}$ & $\mathrm{Ni}$ \\
\hline Old (a) & $\stackrel{m}{\frac{m}{8}}$ & $\begin{array}{l}\text { ڤ్ర } \\
\stackrel{8}{0}\end{array}$ & $\begin{array}{l}\infty \\
\infty \\
\infty \\
0 \\
0\end{array}$ & $\underset{0}{\stackrel{m}{\Xi}}$ & 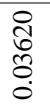 & $\begin{array}{l}m \\
8 \\
8\end{array}$ & $\begin{array}{l}\hat{\delta} \\
\text { } \\
0\end{array}$ & $\begin{array}{l}\vec{n} \\
8 \\
8 \\
0\end{array}$ & $\begin{array}{l}8 \\
8 \\
0 \\
0 \\
0\end{array}$ & 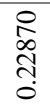 & 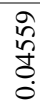 \\
\hline New (b) & 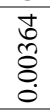 & 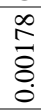 & $\begin{array}{l}0 \\
\infty \\
\infty \\
0 \\
0 \\
0\end{array}$ & $\begin{array}{l}8 \\
8 \\
0 \\
8 \\
0 \\
0\end{array}$ & 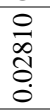 & $\begin{array}{l}0 \\
0 \\
11 \\
6 \\
0\end{array}$ & $\begin{array}{l}\hat{n} \\
\text { so } \\
0 \\
0\end{array}$ & $\begin{array}{l}F \\
8 \\
8 \\
0\end{array}$ & \begin{tabular}{l}
$\infty$ \\
0 \\
\multirow{1}{0}{} \\
0 \\
0
\end{tabular} & $\frac{a}{\stackrel{a}{0}}$ & $\begin{array}{l}\text { ㄱ. } \\
\text { ळे } \\
\text { ᄋ }\end{array}$ \\
\hline $\begin{array}{c}\text { Standard NF EN } \\
601[7]\end{array}$ & & & $\stackrel{8}{8}$ & & $\underset{i}{8}$ & $\stackrel{\wp}{0}$ & $\begin{array}{l}n \\
\stackrel{\leftrightarrow}{*}\end{array}$ & n̊ & $\stackrel{0}{0}$ & กิ & $\underset{\dot{\theta}}{8}$ \\
\hline
\end{tabular}

Examination of the chemical composition shown in Table 2 reveals the following points. The two samples cut from an old used and newly melted pot presented the same chemical elements. The proportion of each chemical element was also similar for the two parts. This result is in agreement with the values reported by Sawadogo et al. [8]. The slight difference in chemical composition observed from one sample to another would be largely due to the diversity of aluminum wastes involved in the traditional metal waste recovery process.

The zinc and copper contents of the samples are lower than those allowed by the standard [7], but are in higher proportions than the other elements. The lead content in the studied samples is low and lower than allowed by the standard. The low lead content reported could be 
highly related to the high casting temperature $\left(830^{\circ} \mathrm{C}\right)$ adopted by artisans in the present work. Lead is not a natural constituent of aluminum alloys. It could have been introduced into the fusion charge by certain engine components. Usually, artisans remove it after pouring the finished parts (pots, ladles, etc.). Indeed, lead is not miscible with almost all alloying elements at room temperature [9]. It therefore separates by a difference in density and solidifies last (its melting point $327^{\circ} \mathrm{C}$ is lower than that of pure aluminum, $660{ }^{\circ} \mathrm{C}$ ). It is then easy to detach it from the part because it does not adhere to the alloy. If lead footprint causes too great defect, the product was recast. However, small particles of lead can still remain in the matrix.

Elements such as nickel, magnesium and sodium are present in low quantity in the studied samples.

The iron content in the samples is lower than that tolerated by the standard. This chemical element is only found in so-called hard alloys (alloys from products such as engine pistons or crankcases rich in magnesium). However, the presence of iron could be induced by a contamination source. Indeed, the steel crucible where the molten aluminum remains at a high temperature (over $650{ }^{\circ} \mathrm{C}$ ) for more than an hour could be a source of contamination. Likewise, the use of tools, made of steel, such as skimmers, ladles could also be another source of contamination. These results were comparable to those obtained by N'DIAYE in his studies on recycled metals waste in Senegal [9].

Other chemical elements such as cadmium $(\mathrm{Cd})$ and chromium $(\mathrm{Cr})$ are in trace amounts. Although cadmium is in trace, its presence in aluminum alloys could contaminate food. The use of aluminum recycled objects, as cookwares is a potential source of food contamination. According to Kim et al. [10] the presence of cadmium in low concentrations in food has toxic effects on the kidneys, skeleton and respiratory system and is classified as carcinogenic to humans. It's therefore important to analyze chemical compositions of different aluminum scraps used to make cookwares and avoid those who contain potential toxic elements.

\section{Microstructural and structural characterizations Optical microscopy}

Fig. 3 shows optical micrographs of two parts taken from old recycled aluminum pot. The microstructure of part (a) was made up of grains with different sizes. These grains have an average size of $28 \mu \mathrm{m}$. Analysis of the microstructure reveals the presence of three phases in different proportions: A bright background which occupies 80 to $90 \%$ of the observed area: this is the aluminum matrix; darker areas widespread in the microstructure likely indicate the virulence of the HF attack; these were probably the silicon seeds even if the silicon was not detected by the AAS method. These results were similar to those obtained by Sawadogo et al. [8]. Dark lines with no defined contours were grain boundaries; they would be composed of a network of fine eutectic particles dispersed in the aluminum matrix [11]. Dark lines reveal the presence of the silicon phase and act as a gash (internal cracks) in the solid solution. According to N'DIAYE [9], the amount of silicon present in the material determines, to a large extent, the microstructure of the alloys studied. The optical micrograph (Fig. 2b) shows large dark areas with grains boundaries which did not appear clearly. These dark areas could also be pores or inclusions formed during the cooling of the cast metal.

Samples from the newly melted pot were also observed under an optical microscope. Fig. 4 presents the micrograph of the newly melted pot (sample (b)). The microstructure of this sample is constituted of a little more ordered grains of different size. The average grain size was $15 \mu \mathrm{m}$. The micrograph (Fig. 4a) reveals the presence of three phases in different proportions as in the case of the old one, with elongated grains and a little more ordered. Analysis of the microstructure shows that it consists of dark areas without grains, which would be pores or inclusions within the matrix (Fig. 4b). There is a difference in the microstructures of the two aluminum alloys. The microstructure of old pot (sample (a)) is constituted of different grains seize of random distribution and some large pores (or inclusions). The microstructure of newly 
melted (sample (b)) has grains of different sizes with somewhat ordered distribution with few large pores (or inclusions). The grain size of old pot was approximately two times larger than that of newly melted pot. The presence of these pores or inclusions would probably be due to the infiltration of the green sand used by the foundry for the casting or from defects in the casting of the molten metal. These alloys (pots) are used for cooking food. When used on stoves they reach high temperatures (above the melting temperature of the alloys), there may be recrystallization and diffusion of inclusions. This could lead to abnormal grain growth and an increase in the volume of inclusions as shown by the micrographs in Fig. 3. These inclusions are possibly primary sources of perforations observed during use.
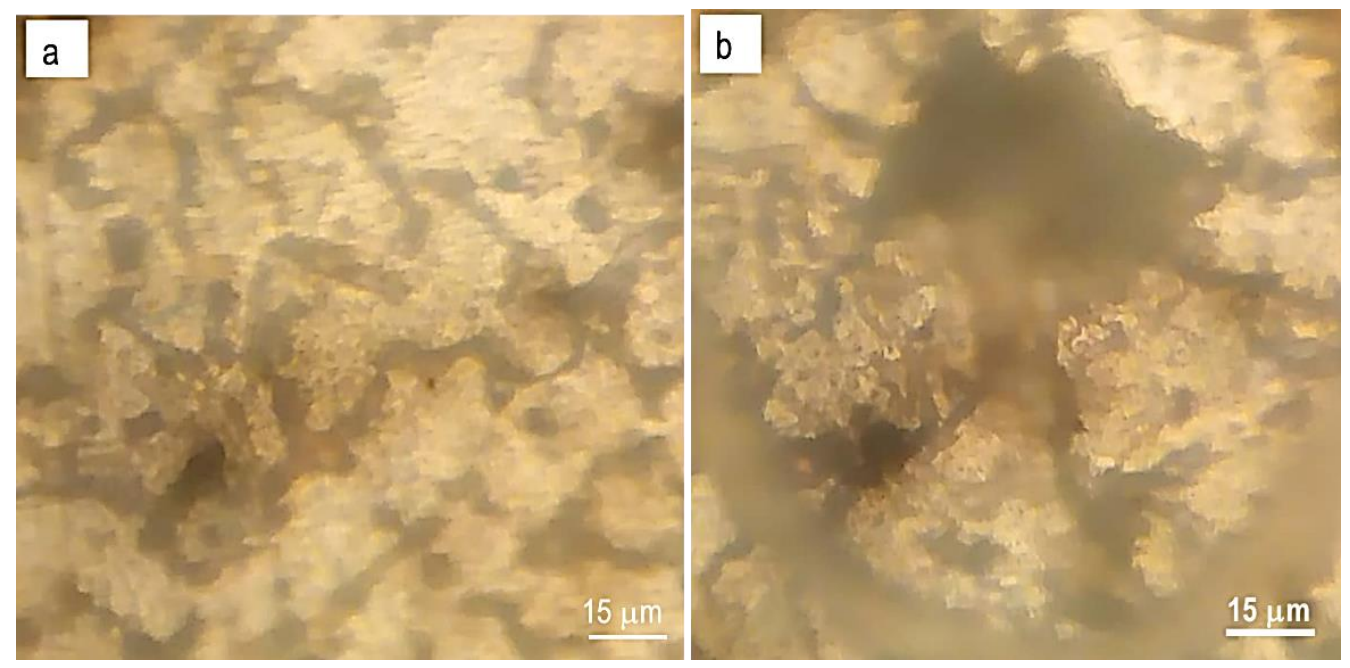

Fig. 3. Optical micrographs of old recycled aluminum pot
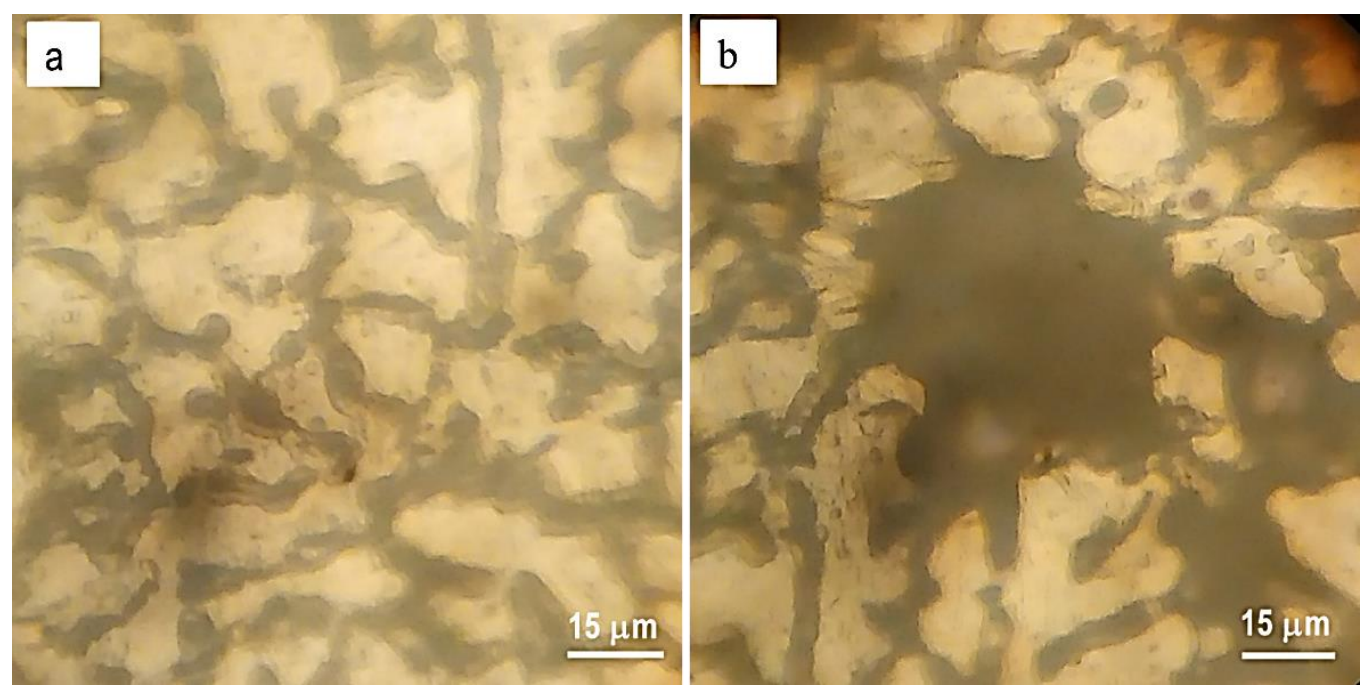

Fig. 4. Optical micrograph of new sample 


\section{X-Ray diffraction}

Fig. 5 shows the XRD patterns of the old recycled aluminum sample. By matching the XRD pattern with JCPS 85-1327 it was found that the major phase present was alpha-aluminum $(\alpha-\mathrm{Al})$. This result was similar to those of pure aluminum reported by Draissia et al. [12].

The presence of another phase than austenite is evident from the diffraction pattern in (Fig. 5). Some peaks can in fact be attributed to bohemite ( $\gamma$-AlOOH) by matching this pattern to JCPDS 21-1307. Austenite is the predominant phase with (111) peak as the main peak. Peaks like (200) and (220) can clearly be identified. The relative intensity of other peaks of $\gamma$-AlOOH, such as (120), (051) and (151) is very low when compared to (111) austenitic peak. Others $\gamma$-AlOOH peaks were overlapped with austenite (111) reflection.

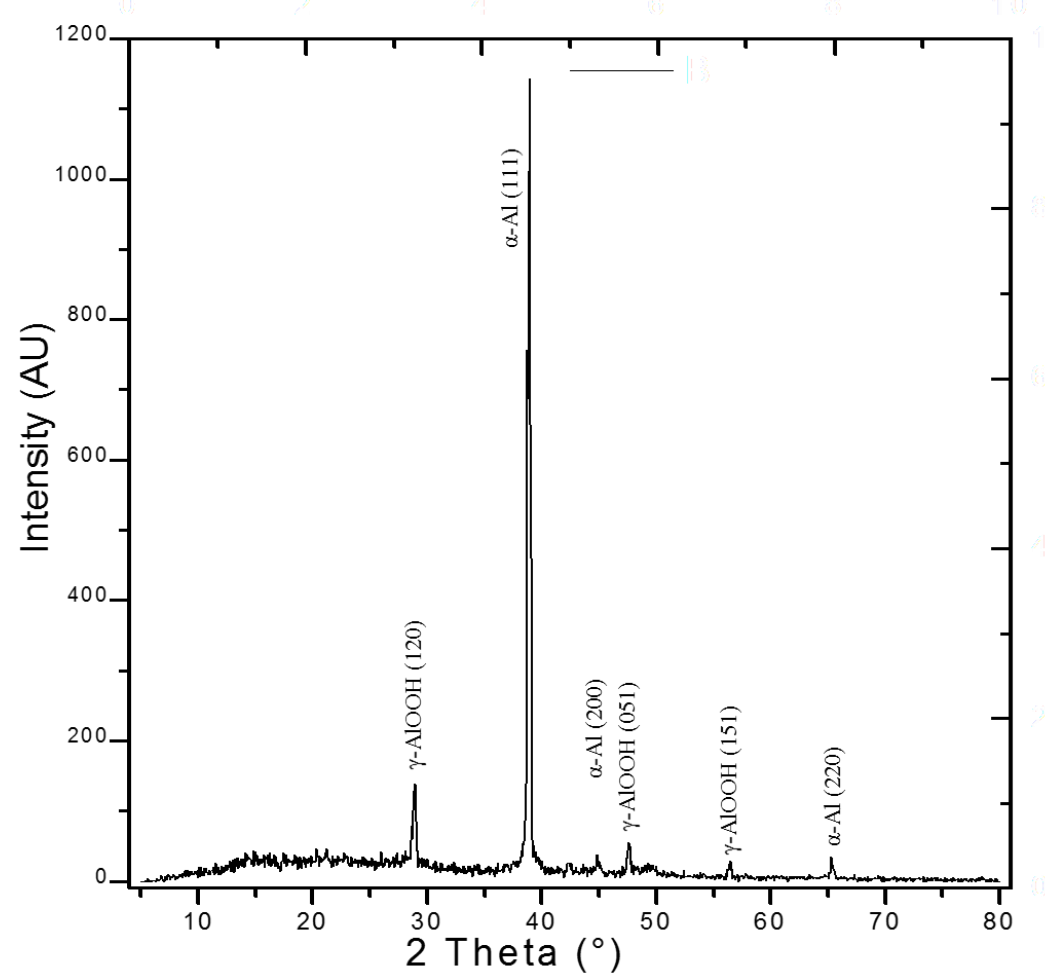

Fig. 5. XRD patterns of old recycled aluminum pot sample

Using Fullprof software the alloy structure was refined by the Rietveld method. The result shows a quite good Rietveld refinement of the Bohemite XRD profile within an orthorhombic crystal structure with lattice parameters of $a=2.876 \mathrm{~nm}, \mathrm{~b}=12.207 \mathrm{~nm}$, and $\mathrm{c}=3.750 \mathrm{~nm}$. For pure aluminum, the theoretical lattice parameter (a) value $4.050000 \AA$ was used to determine the refined value. This refined value was $4.063154 \AA$. The difference between these two values was probably due to the effect of other alloying elements as indicated by the results of the chemical analysis of atomic absorption spectrometry (AAS). The presence of chemical elements such as $\mathrm{Mg}$ and Si reveals probably the formation of intermetallic phase like $\mathrm{Mg}_{2} \mathrm{Si}$. $\mathrm{Mg}_{2} \mathrm{Si}$ and inclusions less noble than aluminum matrix have an anodic behavior and corrode while the matrix is intact around them. This galvanic corrosion is probably one of the causes of perforations observed during the use of domestic recycled aluminum objects. Another cause of perforations could be due to sodium chloride used as cooking salt. Indeed, aluminum oxidation happens faster than that of steel, because aluminum has a really strong affinity for oxygen. Rather than flaking though, aluminum oxide just forms a hard, whitish-colored surface layer. Aluminum atoms bonded with 
oxygen in the form of $\mathrm{Al}_{2} \mathrm{O}_{3}$ or $\gamma-\mathrm{AlOOH}$ and leads to the formation of oxide films which stops corrosion process.

Scratching this oxide layer exposes bare metal, and the process begins again. It won't cat the metal away through, except if chlorides or sulfides are around they'll attack the aluminum oxide layer and leads to pitting corrosion.

\section{Conclusion}

This work aimed to determine the physico-chemical parameters of artisanal recycling of aluminum. The quality of the finished products strongly depends on the quality, quantity of aluminum scrap, knowledge and experience of craftsmen. The results are even quite surprising in terms of the manufacturing quality of the products, given the resources available. The quality of the finished products was confirmed by the analysis carried out in the present work.

Atomic absorption spectrometry (AAS) indicated that the samples studied contain mostly aluminum, zinc, copper, magnesium, some traces of lead and cadmium. On the microstructural level, the samples of kitchen utensils, although diversified in terms of chemical composition, are all made up of an aluminum matrix, which occupies 80 to $90 \%$ of the observed area. To avoid the presence of toxic components in cookware's a preliminary chemical analysis should be made to eliminate aluminum wastes containing toxic elements such as $\mathrm{Cd}$ and $\mathrm{Pb}$. Some inclusions are also observed in the microstructure These inclusions under the combined effect of water, heat, and elements such as sodium chloride used as cooking salt facilitate corrosion and are therefore locations where the observed perforations occur. X-ray diffraction (XRD) confirms the presence of alpha aluminum, with a refined lattice parameter of $4.063154 \AA$ and the most intense peak observed at an angle of $38.86^{\circ}$ in $2 \theta$. Some less intense diffraction peaks were depicted as bohemite $\gamma-\mathrm{AlOOH}$ which could be a product of aluminum oxidation forming a protective film.

A complete chemical analysis of the most common aluminum waste should be done in order to allow craftsmen to sort it out for the manufacture of a specific alloy. This study ultimately aims to bring as far as possible improvements and ways to increase the quality of alloys manufactured by founders.

For a better use of aluminum waste, in order to improve the quality of kitchen utensils alloys, which is strongly linked to the chemical composition of the alloys; the craftsmen will have to make a judicious sorting, after collection to select the most suitable waste to be used for the artisanal pots manufacturing.

\section{References}

[1] O. A. Alabi and Y. M. Adeoluwa, Production Usage, and Potential Public Health Effects of Aluminum Cookware: A Review, Ann. Sci. Technol., 2020, 5(1), pp. 20-30, 2020, doi: 10.2478/ast-2020-0003.

[2] E. Okunna, Traditional pottery practice in contemporary Niageria. Nigeria Craft and technique Nigeria Craft Forum, Ind. Disingn Program. FUTA Akure, 2004, 1(2), pp. 23-26.

[3] O. A. Gabriel and O. A. Yames, Forged aluminum pot production as a vocation and its economic impetus, Mediterr. J. Soc. Sci., 2013, 4(12), pp. 61-65, doi: 10.5901/mjss.2013.v4n12p61.

[4] A. Mathee and R. Street, Recycled aluminium cooking pots: a growing public health concern in poorly resourced countries, BMC Public Health, 2020, 20(1), pp. 1-5, doi: 10.1186/s12889-020-09485-9.

[5] J. D. Weidenhamer et al., Metal exposures from aluminum cookware: An unrecognized public health risk in developing countries, Sci. Total Environ., 2017, 579, pp. 805-813, doi: 10.1016/j.scitotenv.2016.11.023. 
[6] S. Adelabu and D. Campbell, Evaluation of Indigenous Technology for Cast Aluminium Cookware Production in Nigeria : a Case Study of User Health Risks From Cookware Made in Saki, no. November, 2014.

[7] DGCCRF, Aptitude au contact alimentaire des métaux et alliages destinés à entrer en contact avec des denrées alimentaires, 2017, 1.

[8] J. Sawadogo, B. Nisol, M. Bougouma, T. Ramde, Caractérisations chimiques des ustensiles de cuisine artisanale en aluminium fabriqués au Burkina Faso : cas de Ouagadougou, Int. J. Biol. Chem. Sci., 2015, 8(6), p. 2813, doi: 10.4314/ijbcs.v8i6.38.

[9] M. N. Babacar, Le recyclage de métaux d'origine industrielle au Sénégal, Ecole centrale de Lyon/ Ecole Supérieure Polytechnique de Dakar, 2006.

[10] H. S. Kim, Y. J. Kim, and Y. R. Seo, An Overview of Carcinogenic Heavy Metal: Molecular Toxicity Mechanism and Prevention, J. Cancer Prev., 2015, 20(4), pp. 232-240, doi: $10.15430 /$ jcp.2015.20.4.232.

[11] J. Sawadogo, B. Moussa, R. Tambi, B. Guel, Caractérisations physico-chimiques de ustensiles de cuisine ( marmites artisanales) fabriqués au Burkina, J. de la Société OuestAfricaine Chim., 2014, 37(June), pp. 18-28.

[12] M. Draissia, H. Boudemagh, and M. Y. Debli, Structure and Hardness of the Sputtered AlCu Thin Films System, Phys. Scr., 2004, 69(4), pp. 348-350, doi: 10.1238/physica.regular. 069a00348.

[13] Badihi-Mossberg, M. Virginia Buchner et al. Electrochemical biosensors for pollutants in the environment, Electroanalysis, 2007, 19, 19-20, 10.

Received: June 08, 2021

Accepted: August 06, 2021 